\title{
Converting Biomass and Waste Plastic to Solid Fuel Briquettes
}

\author{
F. Zannikos, ${ }^{1}$ S. Kalligeros, ${ }^{2}$ G. Anastopoulos, ${ }^{1}$ and E. Lois ${ }^{1}$ \\ ${ }^{1}$ Fuels and Lubricants Technology Laboratory, School of Chemical Engineering, National Technical University of Athens, \\ 9 Iroon Polytechniou Street, Zografou Campus, 15780 Athens, Greece \\ ${ }^{2}$ Fuels and Lubricants Technology Laboratory, Hellenic Naval Academy, End of Hatzikiriakou Avenue, 18539 Piraeus, Greece \\ Correspondence should be addressed to S. Kalligeros; sskalligeros@hna.gr
}

Received 9 August 2012; Accepted 1 October 2012

Academic Editor: Yoon Y. Lee

Copyright (C) 2013 F. Zannikos et al. This is an open access article distributed under the Creative Commons Attribution License, which permits unrestricted use, distribution, and reproduction in any medium, provided the original work is properly cited.

\begin{abstract}
This work examines the production of briquettes for household use from biomass in combination with plastic materials from different sources. Additionally, the combustion characteristics of the briquettes in a common open fireplace were studied. It is clear that the geometry of the briquettes has no influence on the smoke emissions. When the briquettes have a small amount of polyethylene terephthalate (PET), the behavior in the combustion is steadier because of the increase of oxygen supply. The smoke levels are between the 3rd and 4th grades of the smoke number scale. Measuring the carbon monoxide emission, it was observed that the burning of the plastic in the mixture with biomass increases the carbon monoxide emissions from $10 \%$ to $30 \%$ as compared to carbon monoxide emission from sawdust biomass emissions which was used as a reference.
\end{abstract}

\section{Introduction}

In cities and other industrialized landscapes, the sources of pollution are predominantly transport, industrial, and domestic activities. These activities are the basic cause of the phenomenon which is commonly referred to as climate change [1]. In response to climate change, the use of biomass fuels is increasing as sustainable and carbon (climate) neutral fuels are sought. Additional to climate factors, increasing market prices of traditional fossil fuels have driven consumer preference towards alternative fuels [2]. Furthermore, the price explosion of oil and gas has given a push to the use of renewable energy resources. The recent switch from conventional to renewable energy sources (RES) and their gradually extensive use is a common feature of the energy policy adopted by the developed world. In Greece, in the middle of the economic crisis, the fuel wood consumption in urban regions presents an increasing trend due to the fireplaces used in residences [3].

Additionally the Directive 2000/76/EC for Waste Incineration is in force which sets the limits and the requirements for the waste incineration [4]. In order to enforce this directive the European Commission has issued the mandate M/298 to European Standardization Organizations to elaborate technical means to conforming to Essential Requirements of this
New Approach Directive. Under this mandate, a number of standards for solid biofuels and solid recovered fuels have been issued. Solid biomass and solid recovered fuels as a combustion fuel encompass solid materials (e.g., wood logs or pieces) [5-8], processed materials (wood chip, pellets) [9], waste products (recycled wood, agricultural byproducts) $[10,11]$, gasified materials (methanization of solid fuels) [12], and liquefied materials (e.g., esterification products) [13]. These fuels can be classified according to their origin and production method (life cycle stage). Primary material is sourced specifically for the purpose of combustion/energy generation, while secondary material has undergone processing to reach its preferred combustion format (e.g., new wood used to make pellets or chips). Finally, tertiary fuels are those derived from materials having already undergone a greater portion of their lifecycle (e.g., recovered building materials). These materials are then recycled, producing pellets, chips, or briquettes for use as combustion fuels [5]. Solid fuels can be burned in a variety of manually and automatically operated burners and boilers. Appliances are classified by their intended use and operational methods (batch fired or automatic). In this study only open fireplaces are addressed. The other household combustion appliances are the focus of undergoing work. Open fireplaces are the simplest class 


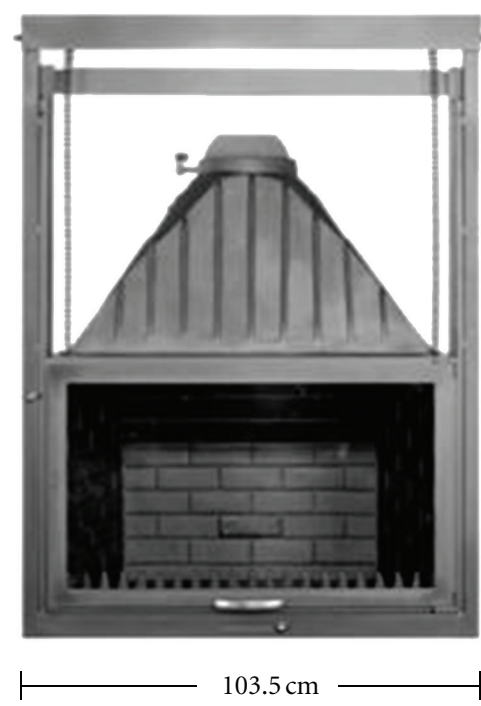

(a)

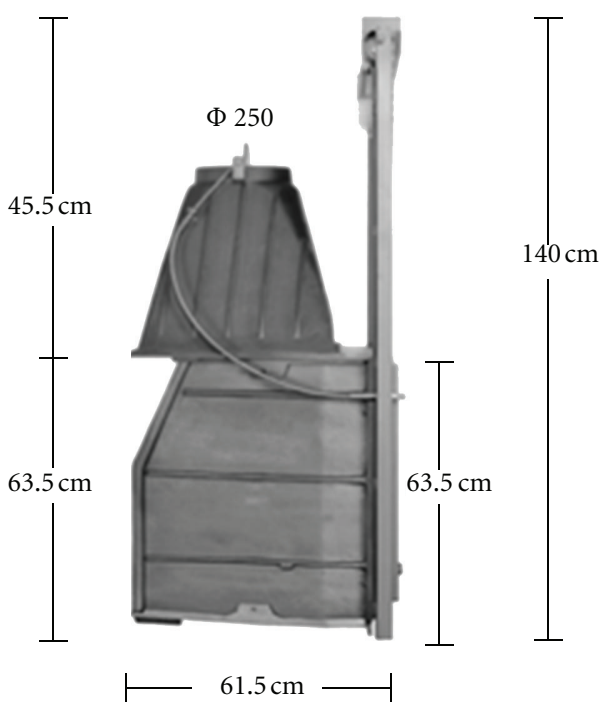

(b)

Figure 1: View of the open fire place installation.

of residential biomass and solid waste combustion appliance with the combustion zone positioned upon a simple grate in a solid form base (i.e., stone or brick). As the name suggests, open fireplaces have at least one exposed side. Exposure of the combustion zone allows for significant heat losses. These losses constrain maximum possible combustion temperatures, limiting combustion rates and leading to high concentrations of particulate and gas-phase emissions [14]. Closed fireplaces are similar in structure to open fireplaces with the addition of side panels closing the gap between the ventilation hood and the base. To facilitate loading and cleaning of the fireplace, a door is fitted to one side of the appliance.

Combustion cycles in residential heating are transient in nature. During transient cycles, there are four clear phases during which emissions vary (ignition, startup, steady state, and burnout.). Of all the phases, the startup phase alone contributes up to $50 \%$ of total particulate matter emissions and up to $70 \%$ of organic material [5]. Soot (carbonaceous) particles are formed via condensation of volatilised organic materials [5]. Aside from appliance type, fuel composition and combustion conditions are known to influence particulate and gas-phase emissions [15]. Combustion conditions can be characterised according to the combustion air-tofuel ratio and the concentration of carbon monoxide emissions [5]. Carbon monoxide is an indicator of combustion efficiency and is known to be detrimental to human health $[16,17]$, while interest in organic carbon and particulate organic matter has increased in recent years as their role in climate and human health impacts is better understood [1820]. High levels of soot, particulate emissions are formed when the air to fuel ratio is near to 1 and the carbon monoxide is high (mean concentration of above $1000 \mathrm{mg} \mathrm{m}^{-3}$ ), while high levels of condensable organics are formed when the air to fuel ratio is greater than 4 and the carbon monoxide is similarly high. Under optimal conditions where the air to fuel ratio is near to 1.5 and the concentration of carbon monoxide is below $100 \mathrm{mg} \mathrm{m}^{-3}$, high mineral to carbon ratio emissions are produced [5].

In this paper a variety of raw materials were used for the manufacturing of briquettes. The raw materials were two different series of used lubricant bottles, bottles from polyethylene terephthalate (PET), high density polyethylene (FIANTHENE 5502), and wax polyethylene, two series of Biomass from kernel, beech sawdust, particle board sawdust, and straw. The manufactured briquettes have been burned in an open fire place where the combustion temperatures have been measured along with the emitted soot in smoke number scale, carbon monoxide, and nitrogen oxide.

The aim of this work is to study the production characteristics of the briquettes for household use. Additionally, the combustion characteristics of the briquettes and their emissions in a common open fireplace were studied.

\section{Materials and Methods}

For the purpose of this study, used empty bottles from lubricants have been collected from car repairing workshops. After the collection their size was shrunk about 5\% with the help of a commercial use shrunk machine manufactured by Carstens $\mathrm{GmbH}$. Additionally, empty bottles from polyethylene have also been collected from a recycling company. Apart from these, two series of biomass from kernel, beech sawdust, particle board sawdust, and straw were ordered. Three patents were applied for the manufacturing of the briquettes, US patent 4561860 [21], US patent 4236897 [22], and the European patent EP0262083 (A1) [23]. With a help of a plastics company's installation using a commercial Adelmann BP 650 press briquettes for fireplaces were produced. All the briquettes have a weight of ca. 300 grams. For the simulation of the combustion an open fire place was installed in the National Technical University of Athens, School of Chemical 


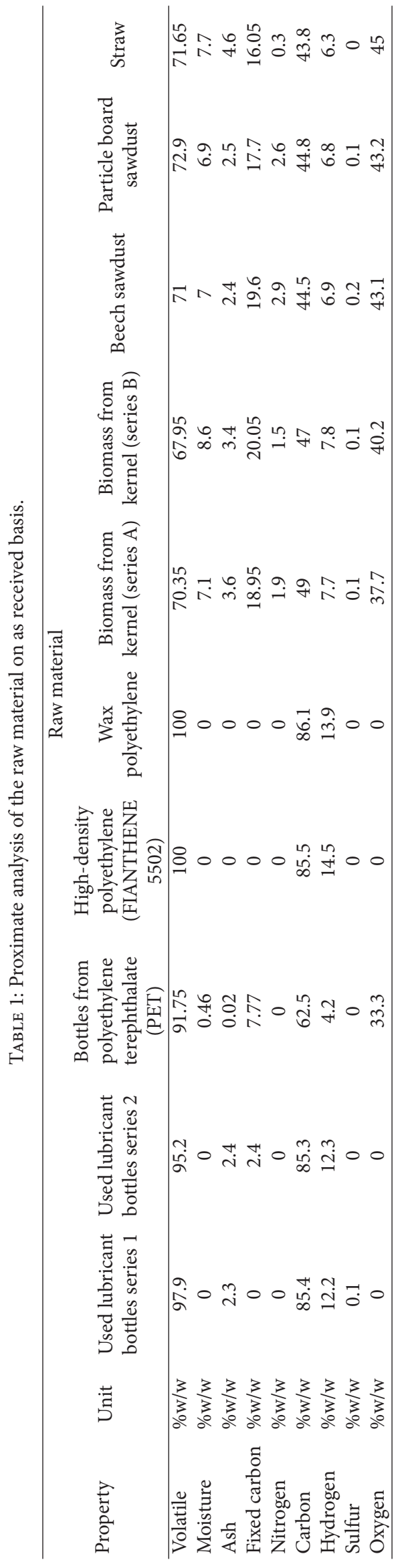




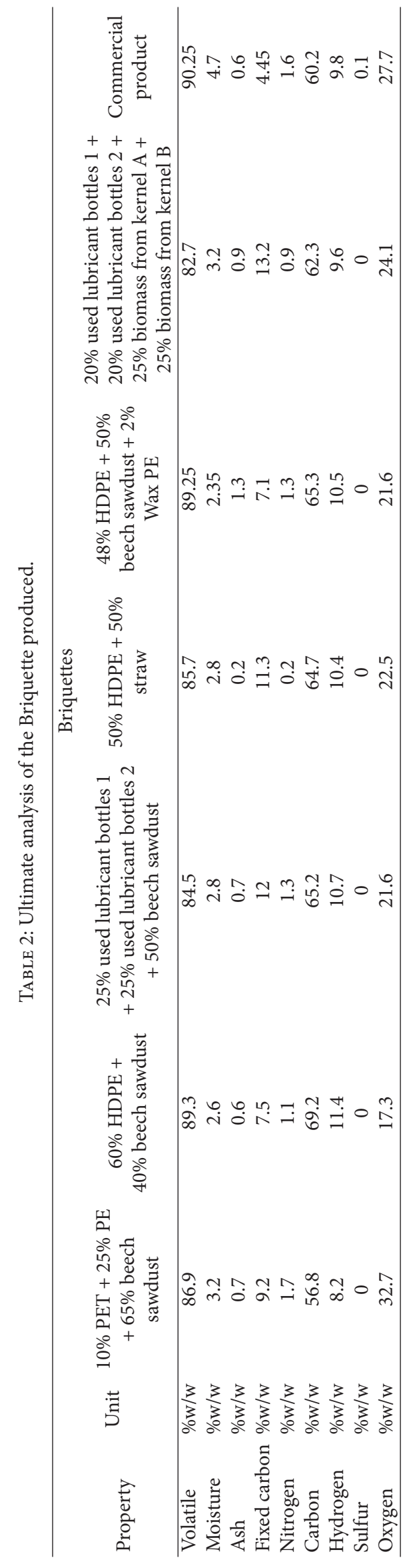


TABLE 3: Geometrical characteristics of the manufactured briquettes.

\begin{tabular}{|c|c|c|}
\hline \multirow[b]{2}{*}{ Briquette } & \multicolumn{2}{|c|}{ Geometrical characteristics } \\
\hline & $\begin{array}{l}\text { Diameter } \\
(d=\mathrm{mm})\end{array}$ & $\begin{array}{c}\text { Height } \\
(h=\mathrm{mm})\end{array}$ \\
\hline Sawdust & 50 & 190 \\
\hline Oak wood & 50 & 190 \\
\hline Beech sawdust & 50 & 190 \\
\hline $60 \%$ HDPE $+40 \%$ beech sawdust & 50 & 190 \\
\hline $70 \% \mathrm{PE}+30 \%$ beech sawdust & 50 & 190 \\
\hline $50 \% \mathrm{PE}+50 \%$ beech sawdust & 50 & 190 \\
\hline $40 \% \mathrm{PE}+60 \%$ sawdust & 50 & 160 \\
\hline $\begin{array}{l}30 \% \mathrm{PE}+70 \% \text { sawdust } \\
(h / d=3,4)\end{array}$ & $\begin{array}{l}50 \\
\text { With a perforated } \\
\text { internal diameter } \\
\text { of } 10 \mathrm{~mm}\end{array}$ & 170 \\
\hline $\begin{array}{l}30 \% \mathrm{PE}+70 \% \text { sawdust } \\
(h / d=3.94)\end{array}$ & 47 & 185 \\
\hline $35 \% \mathrm{PE}+65 \%$ sawdust & 50 & 175 \\
\hline Commercial product 1 & 50 & 185 \\
\hline Commercial product 2 & 55 & 180 \\
\hline $10 \%$ PET $+25 \% \mathrm{PE}+65 \%$ sawdust & 50 & 180 \\
\hline $30 \% \mathrm{PET}+25 \% \mathrm{PE}+65 \%$ sawdust & 50 & 180 \\
\hline $15 \% \mathrm{PET}+30 \% \mathrm{PE}+55 \%$ sawdust & 50 & 180 \\
\hline $\begin{array}{l}7.5 \% \mathrm{PET}+27.5 \% \mathrm{PE}+65 \% \\
\text { sawdust }\end{array}$ & 50 & 180 \\
\hline
\end{tabular}

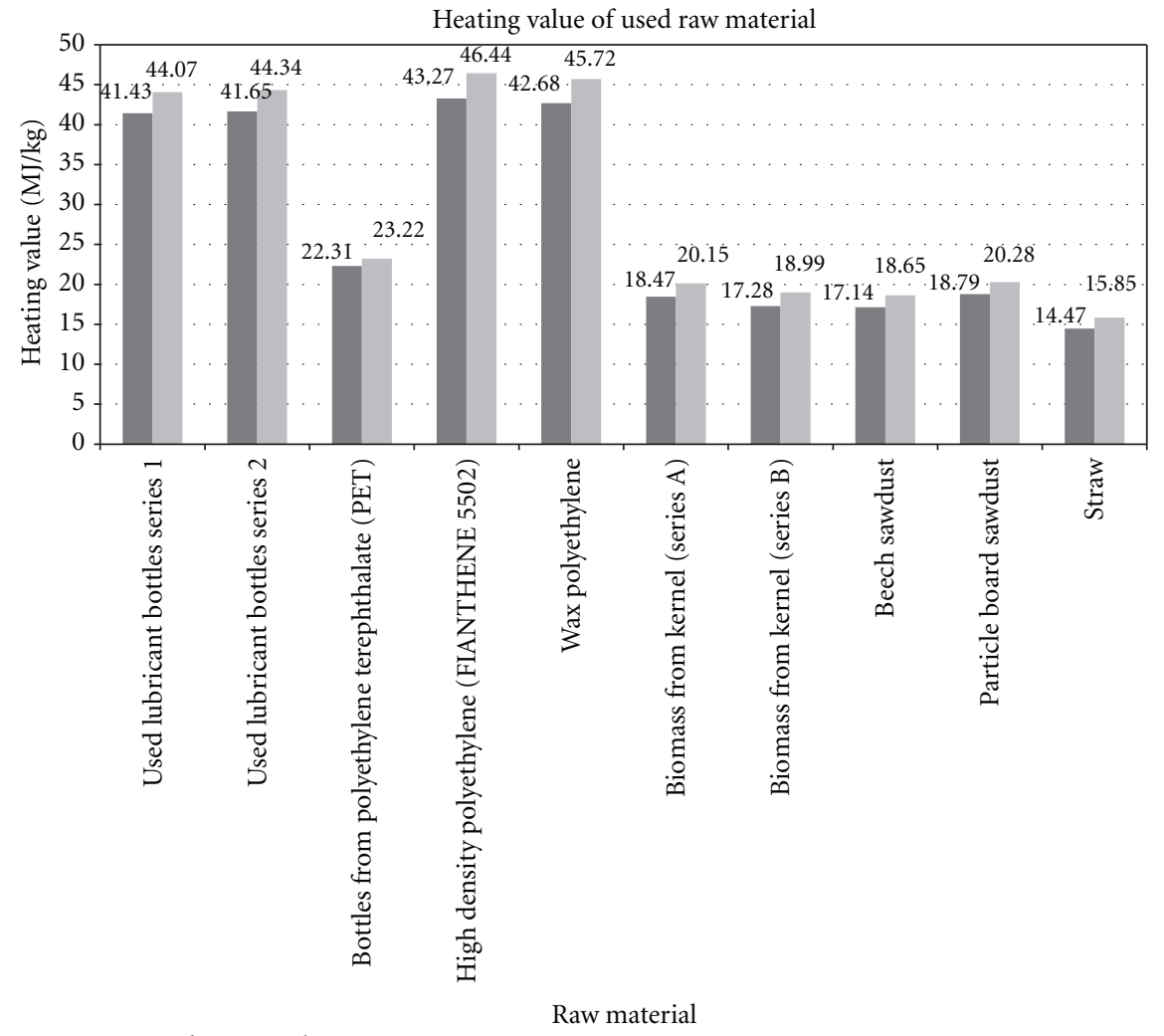

Low heating value

- High heating value

Figure 2: High and low heating value of the selected raw material. 


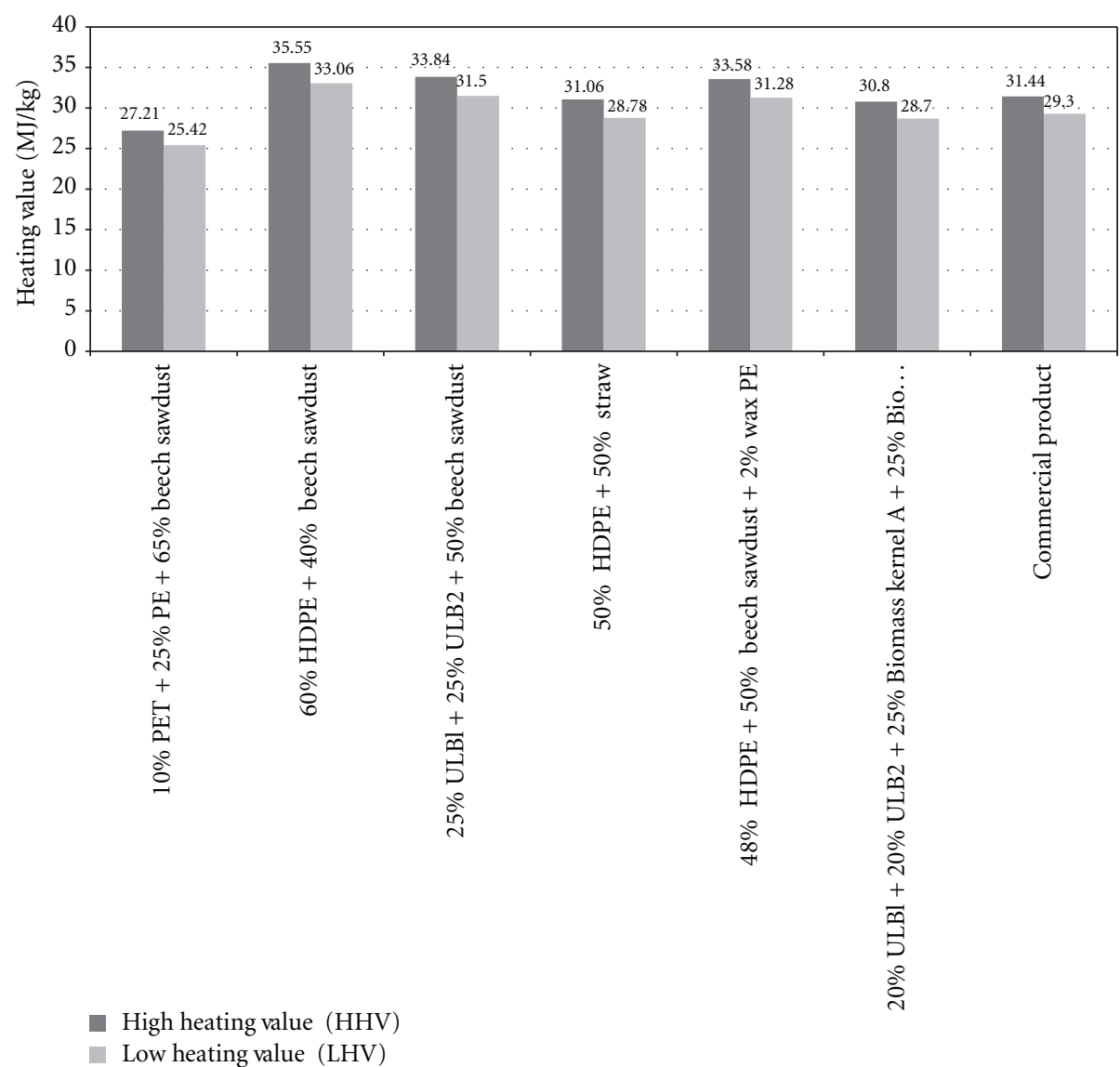

FIGURE 3: High and low heating value of the briquettes which were manufactured from the selected raw material compared with a commercial product.

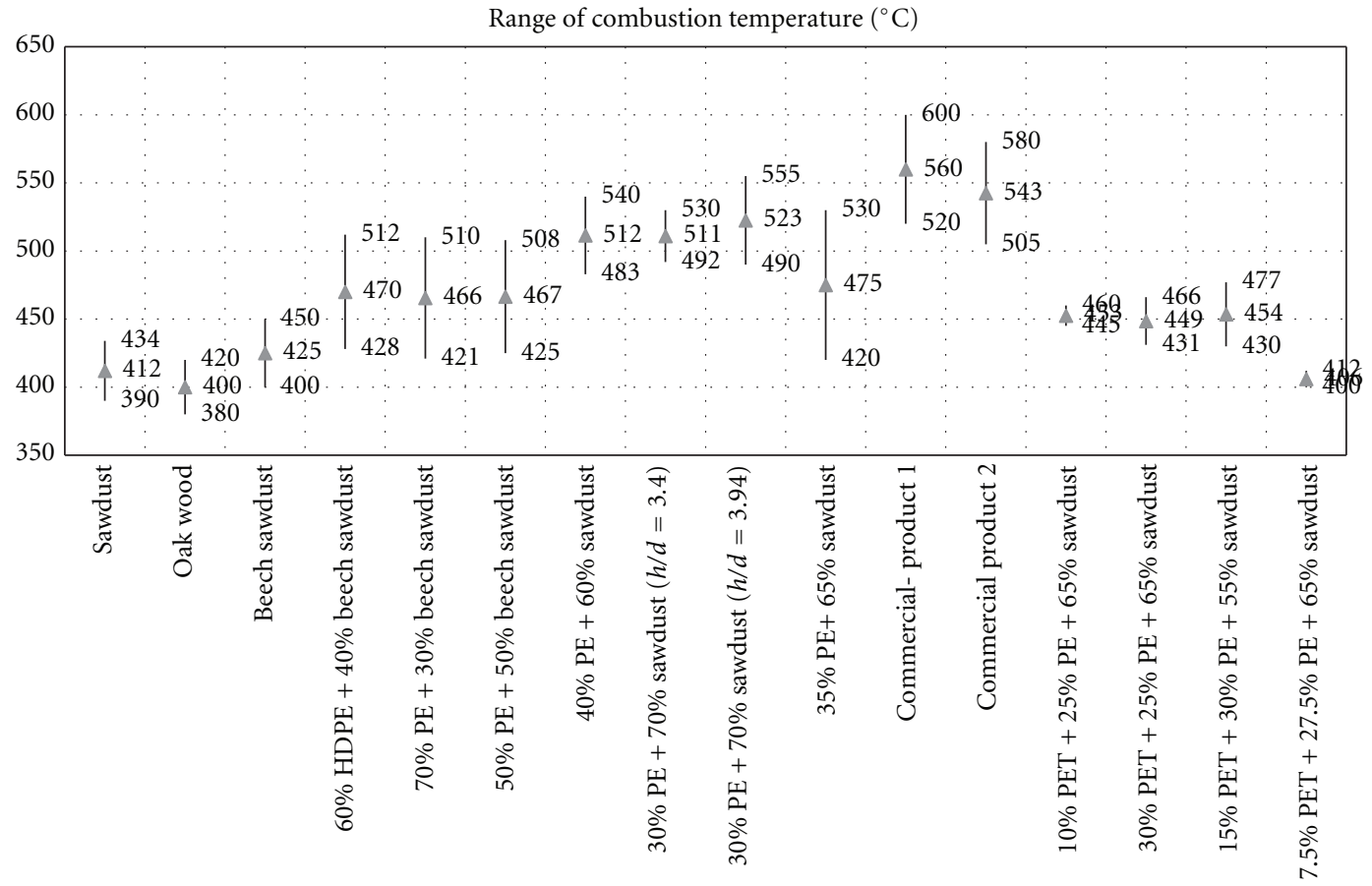

FIGURE 4: Range of combustion temperature in the open fireplace. 
Engineering, Fuels and Lubricants Technology Laboratory. The installation has been traced in Figure 1.

The raw material and the manufactured briquettes have been analyzed and the key properties (volatile matter, moisture, ash, and fixed carbon) have been examined. A Carlo Erba 1108 CHNS-O elemental analyzer was used to determine the content of carbon (\%wt.), hydrogen (\%wt.), nitrogen (\%wt.), and sulfur (\%wt.) in the raw material and in the produced briquettes. The results are presenting in Tables 1 and 2, respectively. These have been examined according to ASTM standard test methods [24-27].

The produced briquettes have all a weight of $300 \mathrm{gr} /$ piece and a cylindrical shape. The geometrical characteristics are presenting in Table 3. All the products were burned in an open fireplace and the temperature of the combustion of each one was measured with the help of KIMO TK 102 (K thermocouple) instrument. The smoke was measured with a typical smoke number scale probe according to ASTM D2156 method [28]. The emissions of carbon monoxide and nitrogen oxides were measured with the help of a Horiba instrument (type MEXA 574-GE, that gauges, CO exhaust emissions near dispersive infrared analyzer) and a $\mathrm{NO}_{x}$ analyzer $\left(42 \mathrm{C} \mathrm{NO}-\mathrm{NO}_{2}-\mathrm{NO}_{x}\right.$ high level analyzer, Thermo Environmental Instruments Inc.), respectively. In order to evaluate them, results are expressed in comparison with the emission from burning $300 \mathrm{gr}$ of pure straw. The fireplace was cleaned after the combustion of each type of briquettes and the residues were removed. Each measurement was taken after one hour of combustion in a cold fireplace.

\section{Results and Discussion}

For this experimental work raw materials of biomass and used bottle for lubricants were collected from various car repair and petrol stations across Athens area. Additionally, plastic bottles of polyethylene terephthalate were collected too.

The high and low heating value of the raw material as received are presented in Figure 2. It can be easily observed that the heating values of used lubricant oil bottles and the polyethylene are higher than the other products. Thus, it was tried to produce briquettes with a standard average weight of ca. $300 \mathrm{gr}$, high heating value of $31,40 \mathrm{MJ} / \mathrm{kg}$ and low heating value of $29,31 \mathrm{MJ} / \mathrm{kg}$.

The heating values of the produced briquettes have been depicted in Figure 3. The rest of the characteristics for these products are presented in Table 2. The higher heating value is observed for the briquette which contains $60 \%$ high density polyethylene and $40 \%$ beech sawdust, whilst the lower heating value is observed for the briquette which contains $10 \%$ polyethylene terephthalate, $25 \%$ polyethylene, and $65 \%$ beech sawdust. All of these products have been burned in an open fireplace.

Figure 4 presents the range of the combustion temperature for each briquette examined. The temperature was recorded when the flame was in full length. The temperature measurement referred to the intermittent flame region which is above the continuous flame region. In this region the flame temperature of the open fireplaces drops as a function

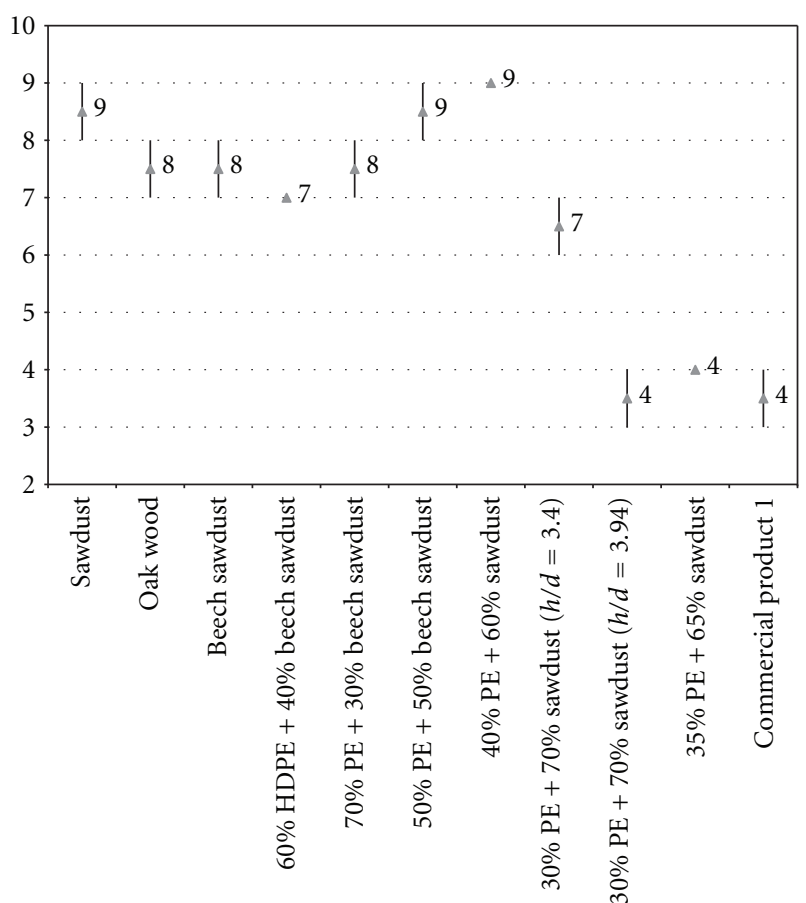

\footnotetext{
Smoke low level

Smoke high level

$\triangle$ Smoke average
}

FIGURE 5: Smoke number level for each briquette.

of distance up the plume. Additionally the thermocouple was unshielded. As it can be easily seen the shorter range appeared when the briquette contained biomass in a percentage of around $65 \%$, polyethylene and polyethylene terephthalate. This is expected because the increased amount of oxygen which these briquettes contain gives more steady behavior during the combustion. The combustion of the above-mentioned briquette appeared to be similar to wood combustion and the briquette retains its original shape.

Figure 5 depicts the smoke number scale for the combustion of the briquettes. If the level of polyethylene is above $40 \%$ then the smoke exceeds the grade nine (9+) in the scale. When the biomass is around $70 \%$ with a percentage of polyethylene of around $30 \%$ the smoke is between seven (7) and eight (8) of the Bacharach scale. It is also observed that when the percentages between biomass and polyethylene shift a bit there was no change in the above-mentioned scale. Additionally, the commercial available product has a smoke scale of nine (9). The comparisons of emissions of carbon monoxide and nitrogen oxides are presented in Figure 6. It is obvious that when the briquette contains plastic and biomass, the amount of carbon monoxide is increased from $10 \%$ to $30 \%$ as compared to pure straw biomass briquette. When the biomass is around $70 \%$ with a percentage of polyethylene of around $30 \%$ the carbon monoxide emissions increased $10 \%$. Furthermore, no change was observed when the percentages between biomass and polyethylene shift a bit. On the contrary with the carbon monoxide emissions the nitrogen oxide emissions are decreased between $20 \%$ and $35 \%$. 


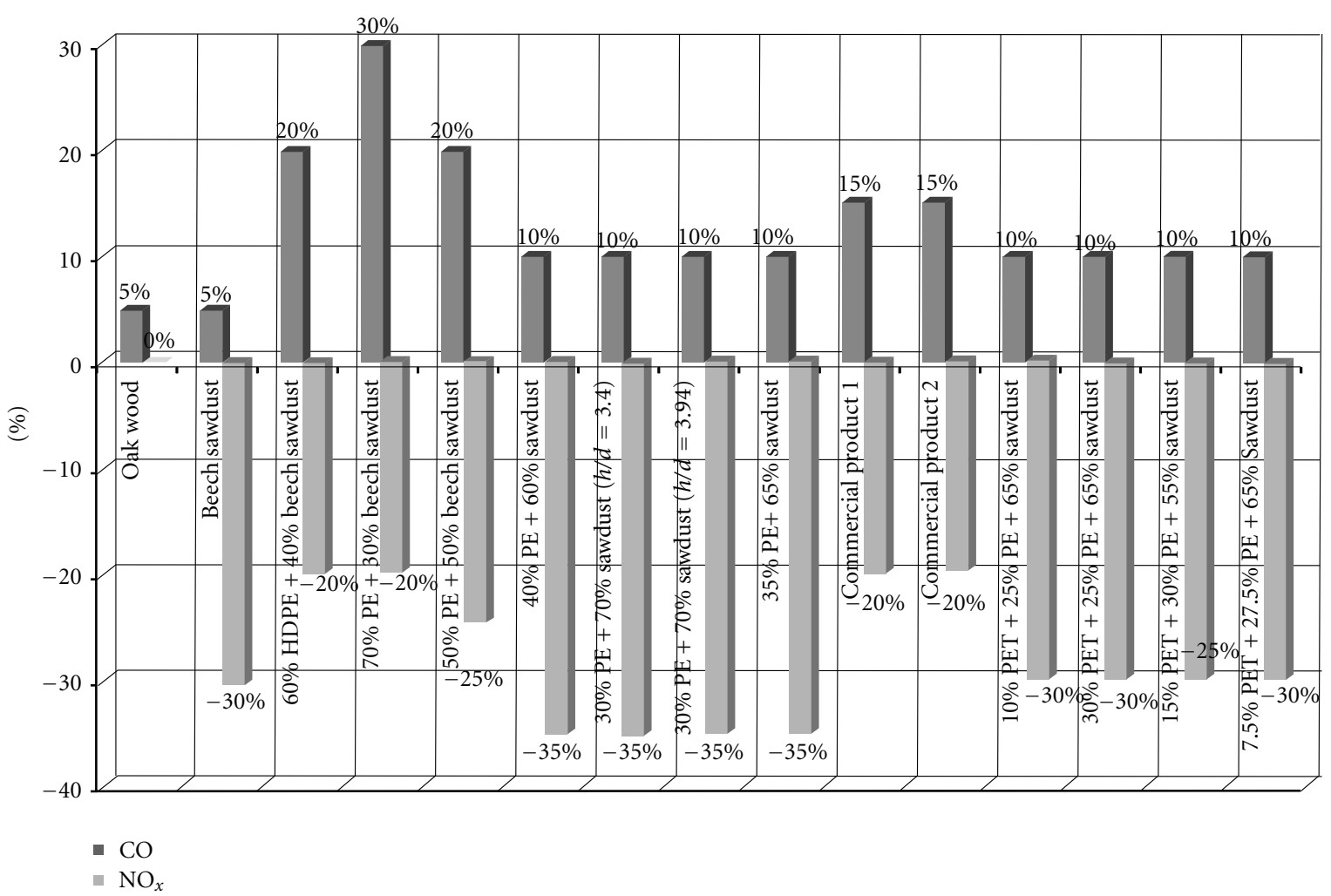

FIGURE 6: $\mathrm{CO}$ and $\mathrm{NO}_{x}$ emissions variation in comparison with the straw emission.

This is expected since for briquettes that contain polyethylene, which has no nitrogen, the amount of nitrogen present in the briquette is significantly lower leading to lower production of nitrogen oxides from the combustion. Similar results are observed when the briquette contains polyethylene terephthalate. At all circumstances the amount of carbon monoxide and nitrogen oxide emissions are better than the emissions from the combustion of the commercial available briquette.

\section{Conclusions}

All briquettes examined have no problem in the combustion procedure. The used plastic material has polyethylene content from $30 \%$ to $70 \%$. The basic observation is that the briquettes with content in polyethylene greater than $40 \%$ burned intensely and lose their basic shape rapidly because of the combustion's high temperature.

On the other hand, when the polyethylene content is higher than $40 \%$ the smoke exceeds the smoke number scale level of $9+$. When the briquettes samples have concentration $70 \%$ biomass and $30 \%$ polyethylene the smoke is between 7 and 8 of smoke number scale. It is also observed that the smoke has no measured alterations when the concentration changes slightly. Additionally, the geometry of the briquettes has no influence to the smoke emissions. Measuring the carbon monoxide emission, it was found that the burning of the plastic in the mixture with biomass increases the carbon monoxide emissions from $10 \%$ to $30 \%$ as compared to carbon monoxide emission from sawdust biomass emissions. When the proportion of biomass to plastic is 70 to 30 the carbon monoxide emissions increased $10 \%$ in relation to the sawdust biomass emissions.

In reverse with the carbon monoxide emissions the nitrogen oxide emissions decreased from $20 \%$ to $35 \%$.

When the briquettes have a small amount of Polyethylene terephthalate (PET) the behavior in the combustion is steadier because of the increased concentration in oxygen. Additionally the smoke levels are between the 3rd and 4th grades of the smoke number scale. These levels are similar to the rest of the biomass samples which were burned into the open fireplace.

\section{References}

[1] IPCC, "Climate change 2007: the physical science basis," in Contribution of Working Group I to the Fourth Assessment Report of the Intergovernmental Panel on Climate Change, S. Solomon, D. Qin, M. Manning, Z. Chen, M. Marquis, K. B. Averyt et al., Eds., Cambridge University Press, Cambridge, UK, 2007.

[2] B. Hillring and M. Trossero, "International wood-fuel trade-an overview," Energy for Sustainable Development, vol. 10, no. 1, pp. 33-41, 2006

[3] E. Zafeiriou, G. Arabatzis, and T. Koutroumanidis, "The fuelwood market in Greece: an empirical approach," Renewable and Sustainable Energy Reviews, vol. 15, no. 6, pp. 3008-3018, 2011.

[4] European Parliament, Directive 2000/76, Waste Incineration Directive, 2000. 
[5] N. K. . Meyer, "Particulate, black carbon and organic emissions from smallscale residential wood combustion appliances in Switzerland," Biomass and Bioenergy, vol. 36, pp. 31-42, 2012.

[6] L. S. Johansson, C. Tullin, B. Leckner, and P. Sjövall, "Particle emissions from biomass combustion in small combustors," Biomass and Bioenergy, vol. 25, no. 4, pp. 435-446, 2003.

[7] L. S. Johansson, B. Leckner, L. Gustavsson, D. Cooper, C. Tullin, and A. Potter, "Emission characteristics of modern and oldtype residential boilers fired with wood logs and wood pellets," Atmospheric Environment, vol. 38, no. 25, pp. 4183-4195, 2004.

[8] T. Nussbaumer, "Combustion and co-combustion of biomass: fundamentals, technologies, and primary measures for emission reduction," Energy \& Fuels, vol. 17, no. 6, pp. 1510-1521, 2003.

[9] I. Obernberger and G. Thek, The Pellet Handbook: The Production and Thermal Utilization of Pellets, Earthscan, London, UK, 2010.

[10] H. Wiinikka, R. Gebart, C. Boman, D. Boström, A. Nordin, and M. Öhman, "High-temperature aerosol formation in wood pellets flames: spatially resolved measurements," Combustion and Flame, vol. 147, no. 4, pp. 278-293, 2006.

[11] O. Sippula, K. Hytönen, J. Tissari, T. Raunemaa, and J. Jokiniemi, "Effect of wood fuel on the emissions from a topfeed pellet stove," Energy \& Fuels, vol. 21, no. 2, pp. 1151-1160, 2007.

[12] C. A. Alzate, F. Chejne, C. F. Valdés, A. Berrio, J. de la Cruz, and C. A. Londoño, "CO-gasification of pelletized wood residues," Fuel, vol. 88, no. 3, pp. 437-445, 2009.

[13] E. DeOliveira, R. L. Quirino, P. A. Z. Suarez, and A. G. S. Prado, "Heats of combustion of biofuels obtained by pyrolysis and by transesterification and of biofuel/diesel blends," Thermochimica Acta, vol. 450, no. 1-2, pp. 87-90, 2006.

[14] S. van Loo and J. Koppejan, The Handbook of Biomass Combustion and Cofiring, Earthscan, 2007.

[15] "Influence of ignition and operation type on particle emissions from residential wood combustion," in Proceedings of the 16th European Biomass Conference and Exhibition, T. Nussbaumer, A. Doberer, N. Klippel, R. Buehler, and W. Vock, Eds., Valencia, Spain, June 2008.

[16] "Online source measurements of organic aerosols from wood combustion with a highresolution aerosol mass spectrometer," in Proceedings of the 28th AAAR Annual Conference, M. F. Heringa, P. F. de Carlo, R. Chirico, A. C. J. Richard, A. Lauber, A. Doberer et al., Eds., Minneapolis, Minn, USA, October 2009.

[17] S. C. van Lith, P. A. Jensen, F. J. Frandsen, and P. Glarborg, "Release to the gas phase of inorganic elements during wood combustion. Part 2: influence of fuel composition," Energy \& Fuels, vol. 22, no. 3, pp. 1598-1609, 2008.

[18] J. P. McCracken, J. Schwartz, N. Bruce, M. Mittleman, L. M. Ryan, and K. R. Smith, "Combining individual- and group-level exposure information: child carbon monoxide in the guatemala woodstove randomized control trial," Epidemiology, vol. 20, no. 1, pp. 127-136, 2009.

[19] O. Boucher and M. S. Reddy, "Climate trade-off between black carbon and carbon dioxide emissions," Energy Policy, vol. 36, no. 1, pp. 193-200, 2008.

[20] IPCC, Climate Change 2007: The Physical Science Basis, 2007.

[21] Brian W. Gulley (Basingstoke GB2), Gilbert J. Williamson, (Grimsby GB2), Richard Q. Carmichael, (Huntley GB2), David F. Cooke, (Wickham GB2), Roderick Taylor (Bourne End GB2), Process and apparatus for production of refuse derived fuel. Patent Number 4561860, December 31, 1985.
[22] Ian F. Johnston, (Corona Del Mar CA), Fuel pellets, Patent Number 4236897, December 2, 1980.

[23] Jackel Chatelain, Heinz Dieter, Process for the manufacture of solid fuel. European Patent EP0262083 (A1), March 30, 1988.

[24] ASTM D5865, Standard Test Method for Gross Calorific Value of Coal and Coke, ASTM International, West Conshohocken, $\mathrm{Pa}$, USA.

[25] ASTM D3173, Standard Test Method for Moisture in the Analysis Sample of Coal and Coke, ASTM International, West Conshohocken, Pa, USA.

[26] ASTM D3174, Standard Test Method for Ash in the Analysis Sample of Coal and Coke from Coal, ASTM International, West Conshohocken, Pa, USA.

[27] ASTM D3175, Standard Test Method for Volatile Matter in the Analysis Sample of Coal and Coke, ASTM International, West Conshohocken, $\mathrm{Pa}$, USA.

[28] ASTM D2156, Standard Test Method for Smoke Density in Flue Gases from Burning Distillate Fuels, ASTM International, West Conshohocken, Pa, USA. 


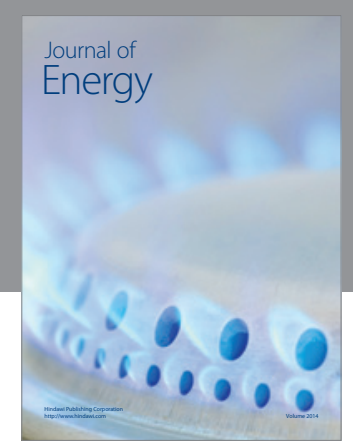

Journal of

Industrial Engineering
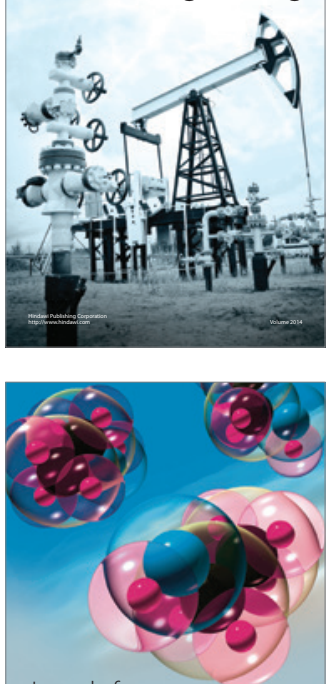

Fuels
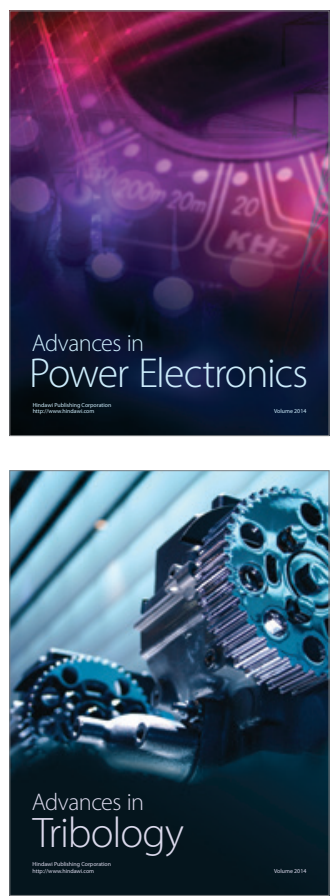

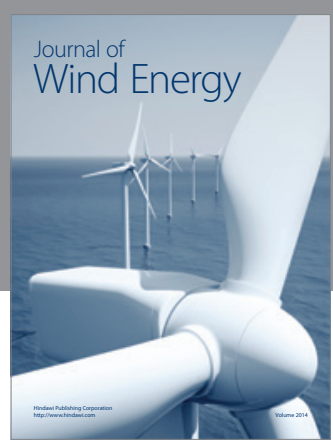

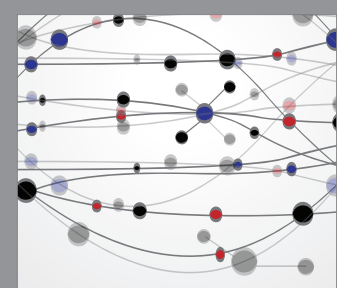

The Scientific World Journal

Submit your manuscripts at http://www.hindawi.com

Journal of

Structures
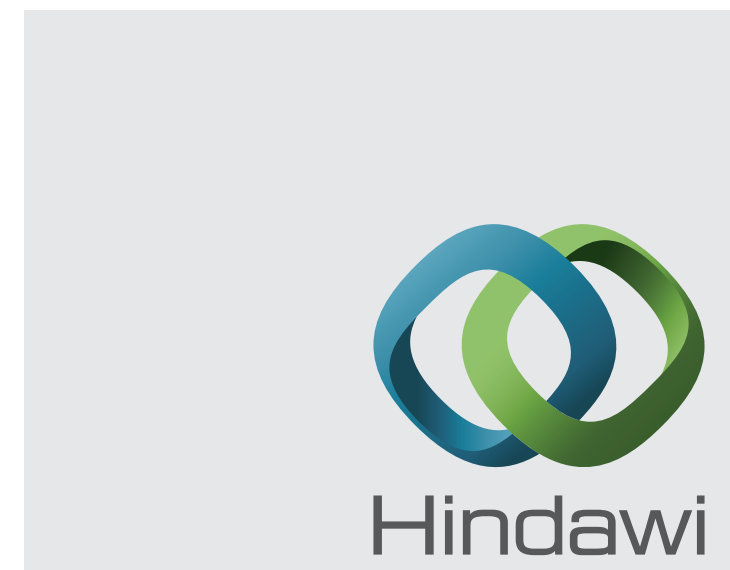

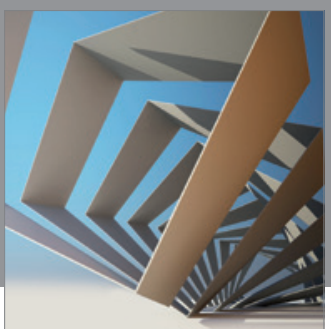

Rotating

Machinery
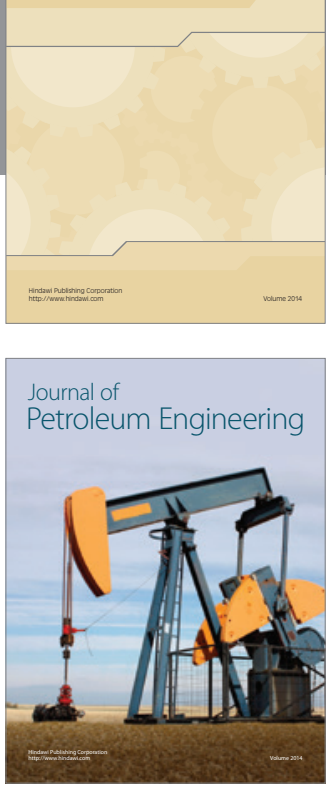

Journal of

Solar Energy
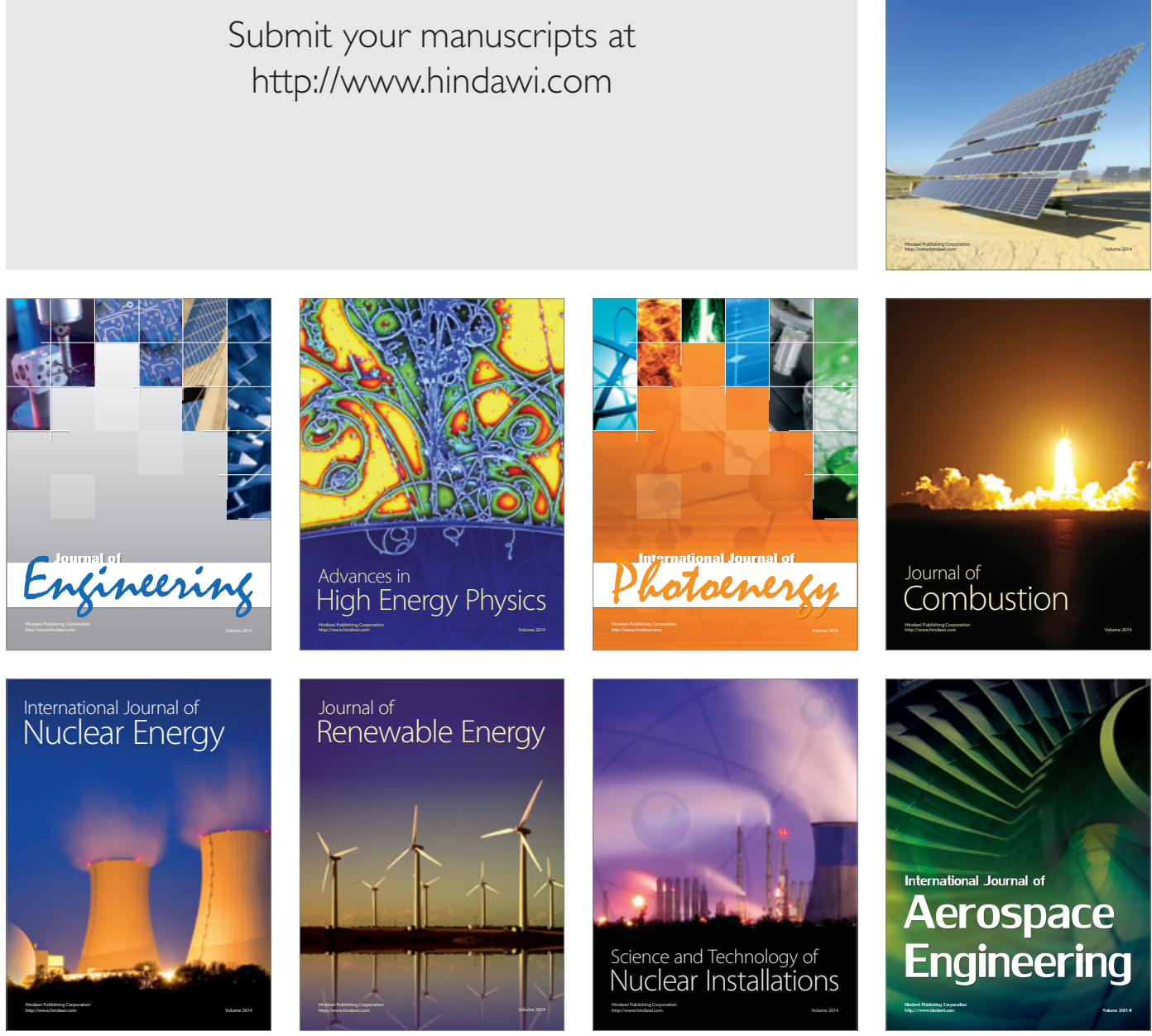